\title{
Traumatic spinal cord injuries in Thailand: an epidemiologic study in Siriraj Hospital, 1989-1994
}

\author{
K Pajareya \\ Department of Rehabilitation Medicine, Faculty of Medicine, Siriraj Hospital, Bangkok, Thailand
}

\begin{abstract}
The records of 219 patients with spinal cord injuries admitted to the Siriraj Hospital, Bangkok from January to December 1994 were reviewed retrospectively. The average patient age was 32.8 years (range $=12-75$ years); the male/female ratio was $5.6: 1$. The most common cause of injury was road traffic accident $(50.7 \%)$, followed by falls $(31 \%)$, assault $(8.7 \%)$ and being hit by moving objects $(7.8 \%)$. As a result of the injury, $52(23.7 \%)$ patients were tetraplegic, $58(26.5 \%)$ were tetrapapetic, $63(28.8 \%)$ were paraplegic and $46(21.0 \%)$ were paraparetic. The mortality rate was $16 \%$. The leading cause of death was a respiratory complication, accounting for $89 \%$ of the total deaths.
\end{abstract}

Keywords: spinal cord injury; epidemiology; Thailand

\section{Introduction}

Traumatic spinal cord injury (SCI) is an important public health problem for several reasons; it usually results in irreversible neurological damage and leads to high rates of morbidity and mortality. The victims require intensive medical care and rehabilitation to maximize their functional capacities. In addition, SCI has a major economic impact on the patient's family and on society. Knowledge of the causes of such injuries could assist the development of prevention and control programmes.

Recent studies have demonstrated certain differences between the causes of SCI in developing and in developed countries. ${ }^{1-4}$ In Thailand, there has been only one study, from Maharaj Nakorn Chiang Mai, a large hospital in the north: ${ }^{5}$ the situation may differ in Bangkok or in rural areas. This study investigated the pattern of SCI in Thailand using records from a major hospital in Bangkok.

\section{Methods}

Hospital records of all patients with traumatic SCI who were admitted to Siriraj Hospital, Bangkok, between January 1989 and December 1994 were analyzed retrospectively. Only first admissions were included.

Spinal cord injury was defined according to Kraus et $a l{ }^{6}$ functional disability was classified according to the American Spinal Injury Association. ${ }^{7}$

\section{Results}

Records were available for 186 males and 33 females, aged from 12 to 75 years. Half of the SCI were caused by traffic accidents and half of those involved motorcycles (Table 1): only nine records indicated drunkeness associated with these accidents. The other major cause of SCI was falling, particularly among construction workers and retired people.

The mean age of patients was similar for injuries due to various causes, except that patients who were injured by falling from the same height were older and most in this group sustained a cervical hyperextension injury (Table 2). There was a positive association between paraplegia and falling from a height (Chisquare test and Fisher exact test, $P<0.05$ ). There was no difference between the number of cervical and thoracic/lumbar injuries due to other causes.

Mortality rate and causes of death

There were 28 deaths during initial acute care hospitalization. The majority $(68 \%)$ were of individuals with a complete cervical cord injury. The leading cause of death was respiratory complications $(89 \%)$. One patient died from an undiagnosed perforated duodenal ulcer and the others died from sepsis of unknown origin.

\section{Discussion}

In this review of patients with SCI admitted to a Bangkok hospital we found that the average age at the time of injury and the age distribution of traumatic SCI were similar to those reported in previous studies. ${ }^{6,8-12}$ Men were more frequently injured than women, with a ratio of $5.6: 1$, this is slightly higher than the results from Chiang Mai $(5: 1),{ }^{5}$ Brazil 
Table 1 Causes of spinal cord injuries

\begin{tabular}{lrc}
\hline Cause & Male & No \\
Fall & & Female \\
$\quad$ from a height & 49 & \\
$\quad$ from the same level & 5 & 11 \\
Traffic accident & & 2 \\
$\quad$ Car, truck & 27 & 6 \\
$\quad$ Motorcycle & 60 & 4 \\
$\quad$ Bicycle & 2 & 2 \\
$\quad$ Pedestrian & 8 & 2 \\
Assault & & \\
$\quad$ Sharp object & 3 & 0 \\
$\quad$ Bullet & 13 & 0 \\
$\quad$ Blown object & 2 & 0 \\
Hit by moving object & 12 & 5 \\
Suicide & 1 & 0 \\
Sport & 0 & 1 \\
Others & 3 & 0 \\
\hline
\end{tabular}

Table 2 Causes of injury, neurological deficit and age at the time of injury

\begin{tabular}{|c|c|c|c|c|c|}
\hline \multirow[b]{2}{*}{ Cause } & \multicolumn{2}{|c|}{ Tetraplegia } & \multicolumn{2}{|c|}{ Paraplegia } & \multirow{2}{*}{$\begin{array}{l}\text { Age at } \\
\text { injury } \\
\text { (years) }\end{array}$} \\
\hline & $I$ & $C$ & $I$ & $C$ & \\
\hline Fall from a height & 9 & 13 & 18 & 20 & 35 \\
\hline $\begin{array}{l}\text { Fall from the } \\
\text { same level }\end{array}$ & 3 & 2 & 2 & 0 & 47 \\
\hline Traffic accident & 36 & 27 & 19 & 29 & 32 \\
\hline Assualt & 4 & 5 & 4 & 6 & 32 \\
\hline $\begin{array}{l}\text { Hit by moving } \\
\text { object }\end{array}$ & 4 & 4 & 2 & 7 & 33 \\
\hline Others & 2 & 1 & 1 & 1 & 31 \\
\hline \multirow[t]{2}{*}{ Total } & 58 & 52 & 46 & 63 & \\
\hline & \multicolumn{5}{|c|}{$(26.5 \%)(23.7 \%)(21.0 \%)(28.8 \%)$} \\
\hline
\end{tabular}

${ }^{*} \mathrm{I}=$ Incomplete. $\mathrm{C}-$ Complete

$(3.9: 1)^{3}$ and Turkey $(3.7: 1)^{13}$ and much higher than the ratio of $2.59: 1$ reported for Switzerland. ${ }^{14}$ The variation is due to different socio-economic and cultural backgrounds, and may change over time, for example the ratio in Japan fell from 9.64:1 in 19691974 (cited in Kuhn) ${ }^{14}$ to $4: 1$ in $1990-1992^{15}$ and the ratio in Denmark ${ }^{16}$ fell from $5.2: 1$ in $1965-1974$ to $3.3: 1$ in $1975-1984$

The leading cause of SCI in this study was traffic accidents, as has been observed in other studies; however, in Western countries most of these accidents involve cars, whereas in Thailand half result from motorcycles. This reflects the high use of motorcycles in Thailand, as occurs in other developing countries, where cars are expensive and public transport is often inadequate.

The second cause of SCI was falling from a height: in Bangkok this is due to accidents in the construction industry, in rural areas it is due to agricultural workers falling from trees while pruning or harvesting produce. In the Chiang Mai study, falling from height was the most common cause of SCI $(43 \%)$, followed by traffic accidents $(28 \%)$; this agrees with the more rural type of population in northern Thailand. Only one injury in this study resulted from sport: this is because few people in developing countries participate in high-risk sports such as rugby, football, horse riding or skiing.

The mortality rate may be higher than is observed in this study, since patients who died before hospitalization were not included.

The results of our study show that prevention campaigns should be targeted at road users, particularly riders of motorcycles, and workers in the construction industry and in agriculture. Stricter safety regulations and good public education are required to reduce the occurrence of accidents and thereby of SCI in Thailand and in other developing countries.

\section{Acknowledgements}

This study was supported by a grant from the Office for Research Promotion and Development, Faculty of Medicine, Siriraj Hospital, Mahidol University. I would like to sincerely thank Mr. Suthipol Udompunturak, statistician for his contribution towards the completion of this analysis.

\section{References}

I Shingu H. Ikata T, Katoh S, Akatsu T. Spinal cord injuries in Japan : a nationwide epidemiological survey in 1990. Paraplegia 1994: 32: 3-8

2 Price C. Makintubee S. Hendon W, Istre GR. Epidemiology of traumatic spinal cord injury and acute hospitalization and rehabilitation charges for spinal cord injuries in Oklahoma, 1988-1990. Am J Epidemiol 1994; 139: $37-47$.

3 Da Paz AC et al Traumatic injury to the spinal cord: Prevalence in Brazilian hospitals. Paraplegia 1992; 30: 636-640.

4 Dixon GS. Danesh JN. Caradoc-Davies TH. Epidemiology of spinal cord injury in New Zealand. Neuroepidemilogy 1993; 12: $88-95$.

5 Kovindha A. Spinal cord injuries in Maharaj Nakorn Chiang Mai Hospital : 5 years retrospectively. Chiang Mai Med Bull 1985; 24: $179-185$. (in Thai)

$6 \mathrm{Kraus}$ JF et al. Incidence of traumatic spinal cord lesions. $J$ Chron Dis 1975: 25: 471492.

7 American Spinal Injury Association (ASIA). Standards for neurological and functional classification of spinal cord injury. Chicago, 1992.

8 Gjone R. Nordlie L. Incidence of traumatic paraplegia and tetraplegia in Norway: a statistical survey of the years 1974 and 1975. Paraplegia 1978; 16: $88-93$.

9 Minaire P et al Life expectancy following spinal cord injury : a ten year survey in the Rhone-Alpes region, France, 1969-1980. Paraplegia 1983; 21: 11-15.

10 Chen CF. Lien IN. Spinal cord injuries in Taipei, Taiwan, 1978 1981. Paraplegia 1985; 23: $364-370$.

11 Pedersen V. Muller PG, Biering - Sorensen F. Traumatic spinal cord injuries in Greenland 1965-1986. Paraplegia 1989; 27: $345-349$.

12 Acton PA et al. Traumatic spinal cord injury in Arkansas, 1980 to 1989. Arch Phys Med Rehabil 1993; 74: 1035-1040. 
13 Dincer $\mathrm{F}$ et al Traumatic spinal cord injuries in Turkey. Paraplegia 1992; 30: 641-646.

14 Kuhn W, Zach GA, Kochlin PH, Urwyler A. Comparison of spinal cord injuries in females and in males, 1979-1981 Basle. Paraplegia 1983; 21: $154-160$.
15 Shingu $\mathrm{H}$ et al. A nationwide epidemiological survey of spinal cord injuries in Japan from January 1990 to December 1992. Paraplegia 1995; 33: $183-188$.

16 Biering - Sorensen F, Pedersen W, Clausen S. Epidemiology of spinal cord lesions in Denmark. Paraplegia 1990; 28: 105-118. 